\title{
Estimating the burden of pediatric HIV in an 'A' category district in India: an epidemiological study
}

\author{
Anju Sinha ${ }^{1 *}$, Reynold Washington ${ }^{2}$, Rajeev Sethumadhavan ${ }^{3}$, Rajaram Subramanian Potty ${ }^{2}$, Shajy Isac $^{4}$, \\ Vasantha Thavraj ${ }^{1}$ and Ravindra Mohan Pandey ${ }^{5}$
}

\begin{abstract}
Background: India lacks epidemiological information on the disease burden of pediatric HIV. The National AIDS Control Program (NACP) estimates the numbers of HIV-positive children as a proportion of adult persons living with HIV. A third of HIV-positive children die before their first birthday and a half before they reach their second birthday. The early detection of HIV is crucial for the prevention of morbidities, growth delays, and death among HIV-positive children.

Methods: The study aimed to estimate the disease burden of pediatric HIV among children in 'A' category district of a high HIV prevalence state. An 'A' category district is defined by the presence of $>1 \%$ HIV prevalence among the general population, as estimated by HIV Sentinel Surveillance. The study used an innovative three-pronged strategy combining cross-sectional and longitudinal methods. The overall burden of pediatric HIV was calculated as a product of cases detected multiplied by a net inflation factor, for each of three strategies.

Results: The existing pool of HIV infection in the district is estimated to be 3266 (95\% Cl: 2621-4197) HIV positive children $<15$ years of age, in a mid-year (2013) projected child population of about 1.4 million, thus giving an HIV prevalence of $0.23 \%$ (Cl: $0.19-0.30$ ) among children (0-14 years of age). The proportion of children among all people living with HIV in the district works out to $10.4 \%$ (Cl: 8.6-13.5\%).

Conclusions: The study estimate of $0.23 \%$ HIV prevalence among children (0-14 years of age) is higher than the NACP estimates (0.02) and is 2.5 higher than the Karnataka state estimate $(0.09)^{22}$. Similarly, the proportion of children among all persons living with HIV in Belgaum district is $10.4 \%$ in this study, as against $6.54 \%$ for India. The study methodology is replicable for other settings and other diseases.
\end{abstract}

Keywords: Estimation, Pediatric HIV, Prevalence, Burden

\section{Introduction}

Globally, the number of persons living with HIV is on the rise and is projected to be an emerging threat to public health. Countries are not on track for the UNAIDS 90-90-90 targets by 2020 and SDG 95-95-95 by 2030 [1]. The targets indicate the proportion of

\footnotetext{
* Correspondence: apradhandr@gmail.com

'Division of Reproductive Biology, Maternal and Child Health, Indian Council of Medical Research, New Delhi, India

Full list of author information is available at the end of the article
}

persons living with HIV who will know their HIV status, are on anti-retroviral treatment, and are virally suppressed. The 2020 estimate of children living with HIV was 1.94 million [2]. There are few estimates of the magnitude of pediatric HIV. Mathematical modeling-based estimates using the Spectrum and Estimation and Projection Package (EPP) model include only the 15-45 age group within the population [3]. In India, a country with 1.3 billion people, children up to 18 years constitute $41 \%$ of the total population [4]. However, India lacks accurate

(c) The Author(s). 2021 Open Access This article is licensed under a Creative Commons Attribution 4.0 International License, which permits use, sharing, adaptation, distribution and reproduction in any medium or format, as long as you give appropriate credit to the original author(s) and the source, provide a link to the Creative Commons licence, and indicate if changes were made. The images or other third party material in this article are included in the article's Creative Commons licence, unless indicated otherwise in a credit line to the material. If material is not included in the article's Creative Commons licence and your intended use is not permitted by statutory regulation or exceeds the permitted use, you will need to obtain permission directly from the copyright holder. To view a copy of this licence, visit http://creativecommons.org/licenses/by/4.0/ The Creative Commons Public Domain Dedication waiver (http://creativecommons.org/publicdomain/zero/1.0/) applies to the data made available in this article, unless otherwise stated in a credit line to the data. 
estimates of the pediatric HIV burden. The National AIDS Control Program (NACP) provides estimates of pediatric HIV that are based on its proportion to adult infections. The NACP uses data available from other countries to arrive at this estimate [5]. The WHO recommended various methods to estimate pediatric HIV including case reporting, household surveys, immunization clinic surveys, in-school and out-of-school surveys, mortality data, and vital registration [6]. These methods have been used in countries with a high HIV prevalence: South Africa, Nigeria, Kenya, Thailand, Argentina, Mozambique, Malawi, Indonesia, and others [7-9]. Similarly, the WHO and UNAIDS recommended measurement of HIV prevalence among children (0-14 years) in settings where the HIV prevalence among women in the reproductive age is $5 \%$ or greater, with high fertility rates, low coverage of prevention of mother to child transmission (PMTCT) services and where resources to conduct a large sample survey among children is feasible [10, 11]. In India, HIV prevalence among women is low and resources for large sample surveys are limited.

The National Family Health Surveys provide estimates of India's adult HIV prevalence but do not include HIV prevalence estimates among children, because of the large sample size that is required [12].

One of the goals of India's National Strategic Plan to end AIDS (2017-2024) is the elimination of mother-tochild transmission (EMTCT) of HIV. Mother-to-child transmission (MTCT) remains the main cause of HIV infection among children in India. Despite the availability of tools and methods to prevent, identify and treat HIV in children, India's performance on this front is sub-optimal. By 2020, 95\% of pregnant women should have received testing for HIV and syphilis and 95\% of estimated HIV-positive pregnant women should have been on antiretroviral treatment (ART) to achieve an MTCT of less than $5 \%$. However, by 2015 , India had registered only $74.2 \%$ of 29.7 million estimated pregnancies and only $59 \%$ of registered pregnant women were tested at least once for HIV, during the antenatal period. Only $45 \%$ of an estimated 35,255 HIV-positive pregnant women received ARV. Out of 10,677 live births among HIV-positive mothers, $85 \%$ of babies were tested at least once in $2016-17$, but only $59 \%$ were tested within 2 months, by which time many babies could have died. The lack of technology-enabled platforms and inadequate utilization of front-line workers for this purpose results in a linkage loss at every level [13]. The 'start free, stay free and AIDS free' platform offers India an opportunity for focused, coordinated action and renewed commitments to end Pediatric AIDS and to eliminate MTCT [14]. In the absence of ART, approximately $30 \%$ of untreated HIV-positive children die before their first birthday and more than $50 \%$ die before they reach 2 years of age [1]. Early diagnosis and timely initiation of treatment, substantially improves survival ${ }^{2}$. Untreated HIV in children results in growth delays that may not be reversed by ART $[15,16]$. It is, therefore, crucial to have reliable estimates of Pediatric HIV, to plan, implement and monitor the coverage of prevention and care programs for children living with HIV.

The Indian Council of Medical Research commissioned a task force study to estimate the burden of Pediatric HIV in a category ' $\mathrm{A}$ ' district of a high prevalence state. The study protocol has been previously published [17]. The NACP defines 'A' category district as one with an HIV prevalence $>1 \%$ among the general population, as estimated by HIV Sentinel Surveillance. This paper describes the results of the task force study.

\section{Methods}

Study design

We followed up a cohort of HIV-positive pregnant women to derive HIV incidence among children exposed to maternal HIV. In addition, cross-sectional analyses were used to estimate HIV prevalence among children (0-14 years) living within families with an index person living with HIV and among children attending outpatient departments from a stratified random sample of public and private health care facilities in the district.

\section{Study setting}

Information regarding study setting, design, and sample size estimation have been previously described ${ }^{17}$. District Belgaum, with an HIV prevalence of $1.43 \%$ in 2011, was selected for the study from among three high prevalence districts in south India. In 2011, Belgaum district had a total population of 4,779,661 (Males: 50.7\%, Females: 49.3\%); 75\% were rural residents and $73.5 \%$ literate (Males: 82.2\%; Females: 64.6\%) [18]. The district Belgaum has 10 sub-district divisions referred to as blocks or talukas. The coverage of antenatal care, including HIV testing as prevention of mother to child transmission (PMTCT) services was high $(>85 \%)$ and the district administration was supportive of the study.

All 971 government and private health care facilities (HCFs) were mapped [19]. We extracted HIV testing data from all 285 HCFs located within ten talukas with stand-alone HIV testing facilities (149 Govt. and 136 private) for the study. The study team visited the identified HCF twice every week for the duration of the study.

In Strategy 1 we used a prospective cohort design to measure the incidence rate of HIV among infants and young children (0-24 months) born to HIV-positive pregnant women. A crude line-list of HIV-positive pregnant women, prepared from the secondary data collected from the HCFs, was refined by removing duplicates and those ineligible (resident outside the district, died, 
currently neither pregnant nor recently delivered a baby). All HIV-positive pregnant women who consented to age-specific HIV blood tests for their infants were enrolled in the study. Trained field investigators contacted the women over the phone and visited them at home or other venues preferred by the woman. The visits were scheduled once a month during pregnancy and until the baby was 24 months old. Age-appropriate HIV testing in infants using DNA PCR dry blood spot (DBS) was conducted at 6-10 weeks and 6-9 months. Antibody-based ELISA tests were conducted at 18-24 months. Field investigators filled data on a mother and child form. Field supervisors validated the data before it entered into the study database.

In Strategies II and III we used a cross-sectional design. In Strategy II, using age-appropriate testing as described above, we examined HIV prevalence among children (014 years) residing in a family with an index person living with HIV. We compiled the list of index persons living with HIV from Integrated Counseling and Testing Centers (ICTC), blood banks, and community-based NGOs in all 10 talukas. The taluka is a sub-district unit, also referred to as a block. We de-duplicated the line-list and organized individuals into family units after field investigators validated this information during a visit to the home of the index person living with HIV. Any person living with HIV, of age 18-49 years, having a biological child aged 0-14 years residing in any taluka of Belgaum, who consented for HIV testing of their spouse and children were considered as eligible and included in strategy II of the study. Field investigators recorded demographic details and HIV testing data on a Family form.

In Strategy III, over a period of 4 months, we screened sick children visiting 10 selected out-patient health care facilities. We selected 10 health care facilities using random sampling, stratified by government and non-government sector, and by primary, secondary, or tertiary levels of health care from four of the 10 talukas. Indian experts adopted the Integrated Management of Childhood Illnesses-HIV (IMCI-HIV) criteria that were applicable only to children $0-5$ years of age, to include its application among children aged 5-14 years, into the algorithm. They also developed operational definitions for each criterion in the algorithm before training health care providers from the four participating talukas. Sick children (0-14 years) presenting with suspected signs and symptoms and satisfying the 'Modified Integrated Algorithm', were tested at health care facilities using age-appropriate HIV tests [20]. The research team visited these facilities once weekly to supervise the process and to compile and track HIV test results. HIV prevalence was calculated for 'sick' children and included a list of the newly detected HIV-positive children.

We derived estimates of children (0-14 years) living with HIV from each of the strategies (1, II \& III) by applying inflation factors. The team of study investigators and the Project Advisory Group derived these inflation factors during a three-day workshop. The inflation factors took into consideration the population characteristics within the district, including total population (adult and child), estimated overall adult HIV prevalence, estimated prevalence among pregnant women, and reported coverage of HIV testing among the antenatal sub-population. The outline of the study design is depicted in Fig. 1.

The Institutional Ethics Committee of St. John's Medical College, Bangalore provided ethics approval, and NACO, the Karnataka State AIDS Prevention Society (KSAPS), and District AIDS Prevention and Control Unit (DAPCU, Belgaum district NACO issued the regulatory approvals.

\section{Study implementation}

We divided the ten talukas in the district into three clusters, each of which had five Field Investigators (FIs) and one supervisor (Senior Research Fellow, SRF). In each cluster, a team of one male and one female FI was given charge of two talukas for strategies 1 and 2 . We appointed one additional FI for the strategy 3 related work. In total, we recruited and trained 14 FIs, over a duration was 10 days. The training was into two sessions that covered both technical information and soft skills for maintaining confidentiality and a gender-sensitive approach. SRFs planned daily visits of FIs validated 5\% of data and verified forms for accuracy and completion. One medically qualified study coordinator supervised the entire field study.

\section{Data management \& statistical analysis}

Two data entry operators double entered all data using Microsoft Access. A statistician cleaned and verified the data for consistency and conducted the analyses using SPSS version 22.0 and STATA version 13.0.

A Project Advisory Group (PAG), constituted by national-level experts, guided the study team to develop the Statistical Analysis Plan (SAP). The primary outcome in Strategy 1 was cumulative incidence, calculated as the number of new infections per total number of children at risk. A child remained at risk till the first positive result by age-appropriate testing. For censored observations, time was the duration of follow-up. The SAP considered the limitations in coverage of services and response rates and guided the determination of the 'Net inflation factor' for each of the three strategies. Under Strategy I,the net inflation factor was derived using the estimated number of pregnancies in the district, proportion of un-tested pregnancies, pregnant mothers not enrolled, and un-tested children. In Strategies II and III, the prevalence of HIV infection among children 0-14 


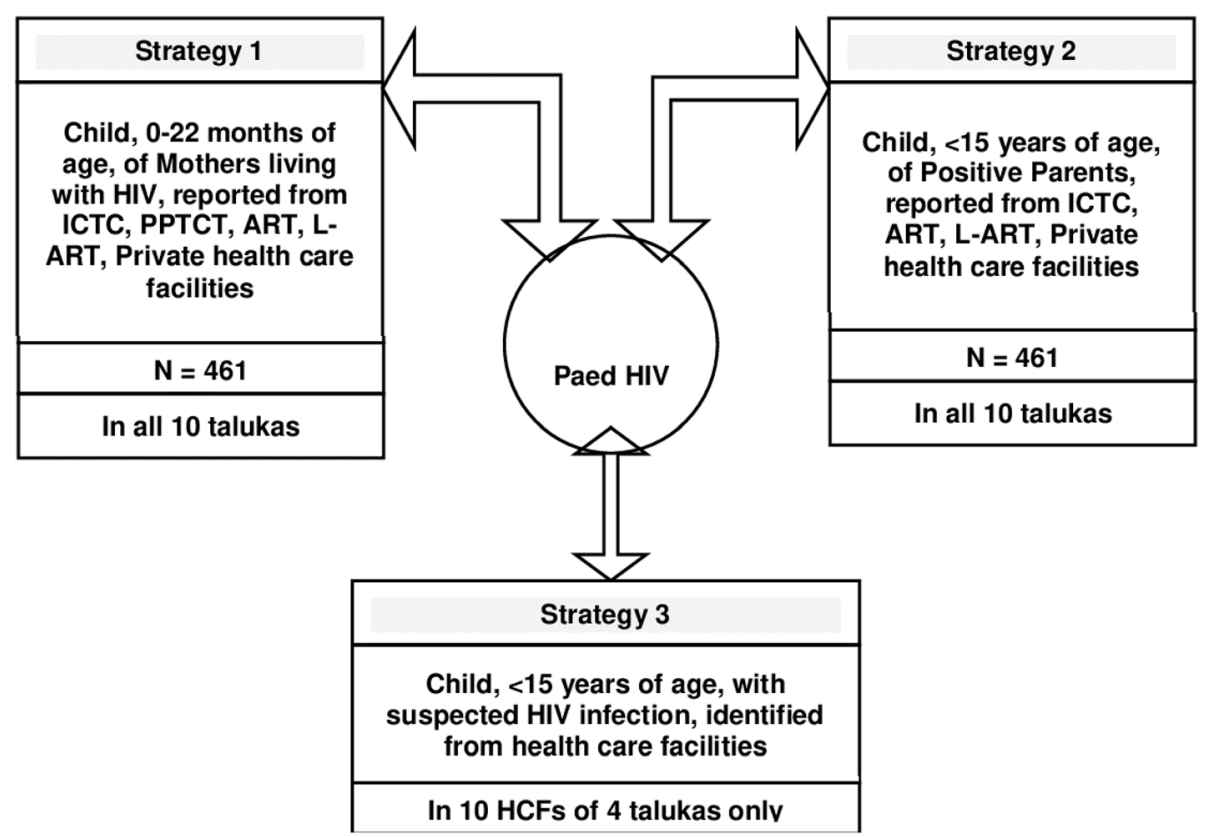

Fig. 1 Outline of the research study

years of age was calculated. In alignment with the SAP, the actual/projected 18-49-year-old population in the study period, the estimated number of $0-14$ year children, the proportion of eligible index persons not recruited, and the proportion of eligible children not tested were factors considered for the inflation process. In Strategy III, the factors considered for Net Inflation factor were: actual/projected $0-14$ year population during the study period, the estimated number of 0-14year-old children experiencing any morbidity, estimated morbid children reaching an HCF for care, estimated children satisfying the screening algorithm, geographical and institutional factors, morbid children not reaching selected HCF but reaching other facilities in the district, and proportions of children un-screened, non-enrolled and not HIV tested. The estimates derived under the strategies were multiplied by the inflation factor to come up with the overall estimate. The steps followed are described along with the results section.

\section{Results}

In Strategy 1, we line listed 750 HIV-positive pregnant women from 285 selected health care facilities. After exclusion of duplicates, those non-resident or who had moved outside the district, died, or were no longer pregnant, we recruited 469 HIV-positive mothers who had delivered between 2011 and 2013, and who consented to participate in the cohort study. The total number of pregnancies among these 469 HIV-positive mothers was 496 , as 27 mothers had a repeat pregnancy during the study period. The outcomes of these 496 pregnancies were 477 (96\%) deliveries with at least one live birth, 10 (2\%) abortions, and 9 (2\%) stillbirths. Among the deliveries with live-births, 10 were twin pregnancies. Thus, the total number of live-born babies was 487 . Of 487 HIV-exposed live-born children, 454 (92.3\%) children were tested at least once, and 38 were found to be HIV positive during follow-up by 24 months of age. Only 400 of 487 babies $(82 \%)$ received the first test between age 6-10 weeks; 23 died even before they reached the age for HIV testing. An additional 41 and 13 babies were tested by the second test and the third test was conducted between age 6-9 months and 18-24 months of age, thus bringing the total number of babies ever HIV tested to 454 (93\%). 10 babies were completely lost to follow-up and remained never tested. The net cumulative incidence rates of vertical transmission of HIV per 100 pregnancies were 2.1 (95\% CI: 1.1-3.8), 5.3 (95\% CI: 3.6-7.8), and 7.8 (95\% CI: 5.7-10.7) at 0-10 weeks, $0-9$ months and $0-24$ months of age, respectively. The cumulative incidence rate by 24 months was calculated to be $4.8 \%$ ((95\% CI: 3.5-6.7).

To calculate the inflation factor at a population level, the following indicators as per the flow diagram (Fig. 2) were conceptualized. The basic parameters were taken from the Census data (Table 1). Based on this, the indicators in the flow diagram were deduced as in Table 2. Based on this inflation factor, the occurrence of new Pediatric HIV infections from MTCT is 41.2 (rounded off to 41) children by the age of 24 months.

In Strategy 2, we recruited 563 households (with 1062 children (Male:565; Female 497) from 671 eligible for 


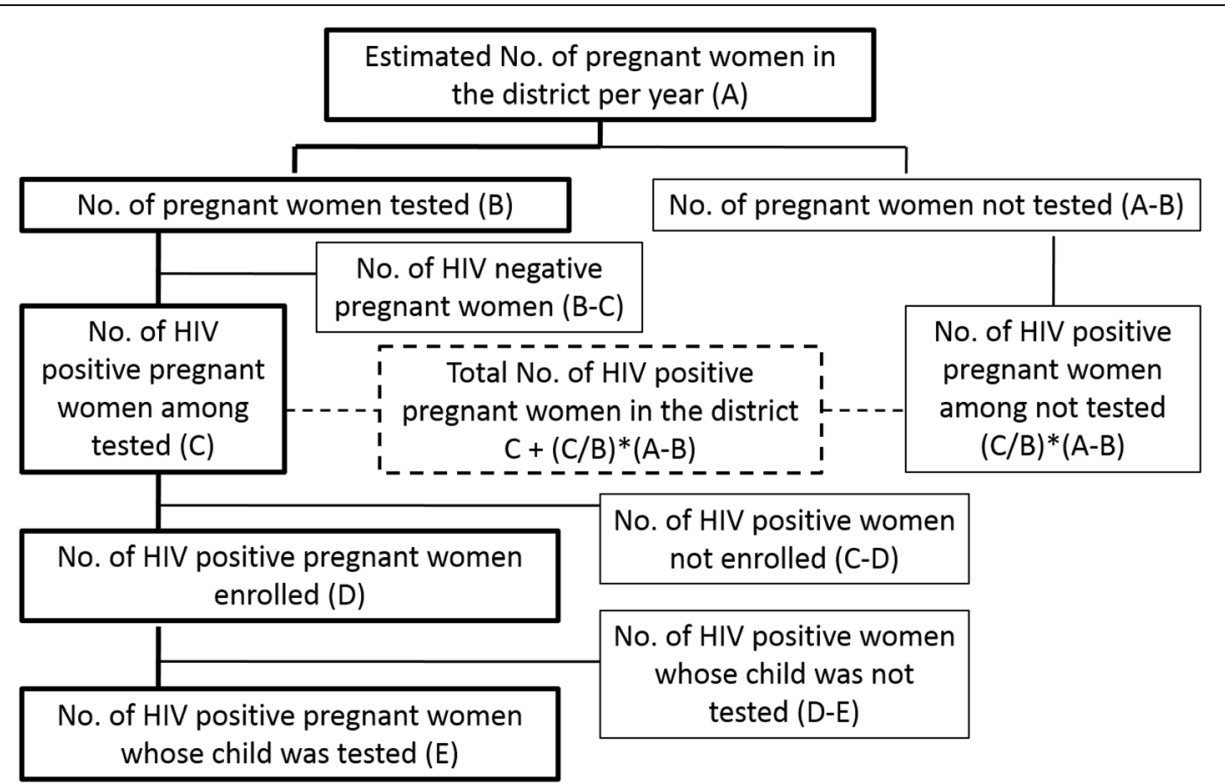

Fig. 2 Conceptual diagram for calculating inflation factors and burden of Pediatric HIV from Strategy 1

recruitment, after eliminating duplication, including those not residents, migrated from the district or could not be contacted. 206 households from Strategy 1, who had children from previous pregnancies, were also included in this sample. Thus, from the 769 Households with 1388 children of age < 15 years, 1241 (90.1\%) were tested for HIV; 131 tested HIV positive, giving an HIV prevalence of $10.6 \%$ ((95\% CI: $8.6-13.5 \%)$. (Males: $12.8 \%$; Females: $8.4 \%$ ). The HIV prevalence was $18.6 \%$ (M: $23 \%$, $\mathrm{F}: 13 \%)$ in the $<5$ year age group and $8 \%$ (M:9.2, F:6.9\%) in the 5-14 years old age group. In order to project these findings to the district population, we used the criteria shown in Fig. 3.

The basic parameters that were required were taken from the Census data available (Table 3). We adopted the calculation shown in (Table 4) for estimating PLHIV in the district of Belgaum. We deduced the inflation factor as shown in the flow diagram in (Table 5).

In Strategy 3, of the total 33,342 children who visited the 10 health care facilities during the study period,
$24,342(73 \%)$ were screened by the trained field investigators. $527(2.2 \%)$ sick children were identified, 509 completed HIV testing requirements. Of these, 97 children turned out to be positive (HIV prevalence 19.1\%), but 86 of them had prior knowledge of their HIVpositive status. The study was, therefore, able to identify $11(2.16 \%)$ new HIV-positive children from among the total of 509 sick children. For Strategy 3, it was assumed that HIV infection would be nil among the 23,815 screened children who did not have any indicative symptoms or social risk criteria for HIV and AIDS. The parameters considered are given in (Table 6).

\section{Estimating the burden of HIV in children $<15$ years}

We estimated the burden of children $0-14$ years by considering all three strategies as shown in (Fig. 4) Data obtained through the cross-sectional approach in the study is indicative of the existing pool of HIV infection among children in the district for the point in time. Assuming other methods of transmission are nil, the vertical

Table 1 Census data for Belgaum district, 2011, considered for calculating inflation factors and burden of Pediatric HIV, Strategy 1

\begin{tabular}{|c|c|c|c|c|}
\hline SI. No. & Parameter & Total & Male & Female \\
\hline 1 & Population, Belgaum district, 2001 & $4,207,264$ & $2,147,746$ & $2,059,518$ \\
\hline 2 & Population, Belgaum district, 2011 & $4,779,661$ & $2,423,063$ & $2,356,598$ \\
\hline 3 & Annual Growth Rate & 0.012756 & 0.012061 & 0.013475 \\
\hline 4 & Projected population, Belgaum district, April 2012 (Mid-study year population) & $4,841,019$ & $2,452,465$ & $2,388,567$ \\
\hline 5 & The proportion of 15-49 years population, 2011 & 0.534365 & 0.536863 & 0.531796 \\
\hline 6 & Crude Birth Rate, Belgaum district, 2011 (Source: CRS, 2011) & 19.71 & & \\
\hline 7 & Estimated pregnancies, Belgaum district, 2012 & 95,416 & & \\
\hline
\end{tabular}


Table 2 Calculation of inflation factors for Strategy 1

\begin{tabular}{lll}
\hline SI. No. & Indicators in the Flow chart for Strategy 1 & Number \\
\hline 8 & No. of pregnant women tested (Source: PPTCT data, Belgaum district, 2012) & 90,070 \\
9 & No. of pregnant women not tested $(=(7)-(8))$ & 5346 \\
10 & No. of HIV positive pregnant women among tested (Source: PPTCT data, Belgaum district, 2012) & 187 \\
11 & HIV positivity among pregnant women $(=(10) /(8))$ & 0.002076 \\
12 & No. of HIV positive pregnant women among those not tested $\left(=(11)^{*}(9)\right)$ & 11 \\
13 & Total no. of HIV positive pregnant women in the district, $2012(=(10)+(12))$ & 198 \\
14 & Total no. of HIV positive pregnant women in the district during the study period (29 months) \\
15 & No. of HIV positive mother-child pairs enrolled in the study \\
16 & No. of enrolled HIV pregnant women whose child was tested & 479 \\
17 & Inflation factor $\left(=[(15) /(16)]^{*}[(14) /(15)]\right)$
\end{tabular}

${ }^{a}$ Footnote: 469 HIV infected pregnant women were recruited from 469 Households $(\mathrm{HH})$. More-than-one-time pregnancies of the same woman during study period $=27$. Hence total HIV infected pregnancies $=469+27=496$. Abortion $=10$; Stillbirth $=9$. Twins $=10$.Total Mother-Child pairs $=496+10=506$. Total live births $=506-19=487$

transmission of HIV (Strategy I) adds to the existing pool. Mortality among HIV-positive children decreases the existing pool. The total number of children in the existing pool of HIV infection in Belgaum district in the study is the sum of children HIV positive in Strategy I and II, and newly identified children from Strategy III, this is given in Table 7 .

Thus, the existing pool of HIV infection in the district works out to be 3266 (95\% CI: 2621-4197) HIV positive children $<15$ years of age, in a mid-year (2013) projected child population of about 1.4 million, thus giving us an overall HIV prevalence of $0.23 \%$ (95\% CI: $0.19-0.30$ ) among children ( $0-14$ years of age). The proportion of children among all people living with HIV in the district works out to $10.4 \%$ (95\% CI: 8.6-13.5\%).

Assuming that other methods of transmission of HIV to children $<15$ years of age group is nil, the net cumulative incidence rate (\%) of vertical transmission of HIV per 100 pregnancies is $4.8 \%$ (95\% CI: $3.5-6.7 \%$ ) by about 24 months of child's age.

\section{Discussion}

This is the first district-wide study estimating the Pediatric HIV burden in India. The findings indicate that Belgaum district had an overall HIV prevalence of $0.23 \%$ among children (0-14 years) and about 3266 children

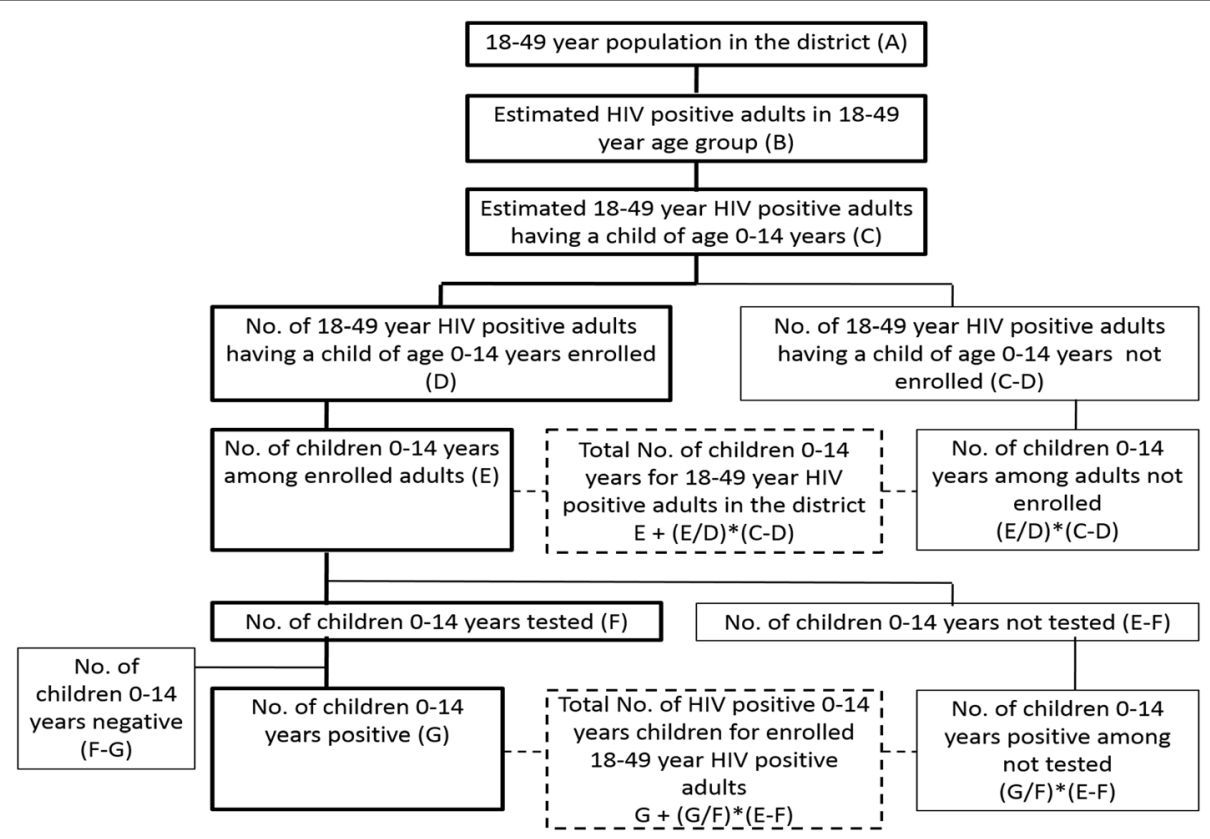

Fig. 3 Conceptual diagram for calculating inflation factors and burden of Pediatric HIV from Strategy 2 
Table 3 Census data for Belgaum district, 2011, considered for calculating inflation factors and burden of Pediatric HIV, Strategy $1 \& 2$

\begin{tabular}{|c|c|c|}
\hline SI. No. & Parameter & Total \\
\hline 1 & $\begin{array}{l}\text { Projected population, Belgaum district, Feb } 2012 \\
\text { (Mid study population) (From Table } 19 \text { above) }\end{array}$ & $4,841,019$ \\
\hline 2 & $\begin{array}{l}\text { The proportion of 15-49years population, Belgaum } \\
\text { district, } 2011\end{array}$ & 0.534365 \\
\hline 3 & The proportion of 18-49years population, 2011 & 0.478696 \\
\hline 4 & $\begin{array}{l}\text { Projected 15-49 years population, Belgaum district, } \\
\text { Feb } 2012\end{array}$ & $2,586,871$ \\
\hline 5 & $\begin{array}{l}\text { Projected adult 18-49 years population, Belgaum } \\
\text { district, Feb } 2012\end{array}$ & $2,317,376$ \\
\hline 6 & $\begin{array}{l}\text { No. of children of age } 0-14 \text { years, Belgaum } \\
\text { district, } 2011\end{array}$ & $1,366,381$ \\
\hline 7 & $\begin{array}{l}\text { Projected children population (0-14 years), } \\
\text { Belgaum district, Feb } 2012\end{array}$ & $1,383,922$ \\
\hline 8 & Child/Adult ratio, Belgaum district, Feb 2012 & 0.597193 \\
\hline
\end{tabular}

living with HIV, during the year 2013, making the proportion of Pediatric infections $10.4 \%$ of all HIV infections in the district. This is about a third higher than the national estimates (based on projections of adult infections) ranging between 6 and 7\% of all HIV infections, during the same period [21, 22]. The results of this study could be generalized to other similar districts with high HIV prevalence, high coverage of HIV screening during pregnancy/delivery, and high levels of treatment coverage among those living with HIV. The results although not generalizable across all districts in India, do provide useful information on how to estimate the burden of Pediatric HIV from existing data by using an excel based software (being published elsewhere).

The GBD framework based on Spectrum and EPP uses multiple methodological improvements, yet faces limitations and biases due to the use of variable data sources. A non-parametric back-calculation method used in Thailand studied HIV/AIDS trends for future predictions. This study reported the use of data adjustments to overcome surveillance reporting issues. Moreover, these methods did not include pediatric age groups $[3,23]$. This study is an effort to derive the pediatric burden estimate from existing data within a district.

The uniqueness of this study is its innovative epidemiological design, using a robust combination of community and facility-level data, the inclusion of private and public sector health facilities, the multi-pronged strategy of using cross-sectional and longitudinal data collection techniques, and the extrapolation to correct for gaps in coverage using inflation factors. In most countries, including India, linkage loss tends to occur at various levels within the PMTCT programs [24]. The study staff supported the program to reduce the gaps in HIV testing and treatment linkages at various levels.
Table 4 PLHIV estimation ${ }^{a}$, Belgaum district

\begin{tabular}{|c|c|c|c|}
\hline $\begin{array}{l}\text { Sl. } \\
\text { No. }\end{array}$ & \multicolumn{2}{|l|}{ Parameter } & Number \\
\hline 9 & \multicolumn{2}{|c|}{ Sex ratio (Source: Census data, 2011) } & 960 \\
\hline 10 & \multicolumn{2}{|c|}{ Percentage of men having high-risk sexual activity } & 6.0 \\
\hline 11 & \multicolumn{2}{|l|}{ Estimated FSWs } & 11,766 \\
\hline 12 & \multicolumn{2}{|l|}{ Estimated MSM T } & 2333 \\
\hline 13 & \multicolumn{2}{|l|}{ Estimated IDUs } & 37 \\
\hline 14 & \multicolumn{2}{|c|}{ Estimated clients $\left(=(1) *[1000 /(1000+(9))]^{*}((10) / 100)\right.$} & 79,190 \\
\hline 15 & \multicolumn{2}{|c|}{ Total high risk population $(=(11)+(12)+(13)+(14))$} & 93,326 \\
\hline 16 & \multicolumn{2}{|c|}{ Remaining $15-49$ years population $(=(7)-(15))$} & $2,493,545$ \\
\hline 17 & \multirow[t]{2}{*}{ HIV prevalence, FSW } & Min & 16.40 \\
\hline 18 & & Max & 27.34 \\
\hline 19 & \multirow[t]{2}{*}{ HIV prevalence, MSM } & Min & 5.51 \\
\hline 20 & & Max & 10.62 \\
\hline 21 & \multirow[t]{2}{*}{ HIV prevalence, IDU } & Min & 2 \\
\hline 22 & & Max & 2 \\
\hline 23 & \multirow[t]{2}{*}{ HIV prevalence, Clients } & Min & 3.85 \\
\hline 24 & & Max & 8.55 \\
\hline 25 & \multirow[t]{2}{*}{ HIV prevalence, ANC } & Min & 0.69 \\
\hline 26 & & Max & 0.95 \\
\hline 27 & \multirow{2}{*}{$\begin{array}{l}\text { Adjusted HIV } \\
\text { prevalence, ANC }\end{array}$} & Min & 0.69 \\
\hline 28 & & Max & 0.95 \\
\hline 29 & \multirow{2}{*}{$\begin{array}{l}\text { Number of HIV positive } \\
\text { FSWs }\end{array}$} & $\operatorname{Min}\left(=(11)^{*}(17) / 100\right)$ & 1930 \\
\hline 30 & & $\operatorname{Max}\left(=(11)^{*}(18) / 100\right)$ & 3217 \\
\hline 31 & \multirow{2}{*}{$\begin{array}{l}\text { Number of HIV positive } \\
\text { MSM }\end{array}$} & $\operatorname{Min}\left(=(12)^{*}(19) / 100\right)$ & 129 \\
\hline 32 & & $\operatorname{Max}\left(=(12)^{*}(20) / 100\right)$ & 248 \\
\hline 33 & \multirow{2}{*}{$\begin{array}{l}\text { Number of HIV positive } \\
\text { IDUs }\end{array}$} & $\operatorname{Min}\left(=(13)^{*}(21) / 100\right)$ & 1 \\
\hline 34 & & $\operatorname{Max}\left(=(13)^{*}(22) / 100\right)$ & 1 \\
\hline 35 & \multirow{2}{*}{$\begin{array}{l}\text { Number of HIV positive } \\
\text { Clients }\end{array}$} & $\operatorname{Min}\left(=(14)^{*}(23) / 100\right)$ & 3049 \\
\hline 36 & & $\operatorname{Max}\left(=(14)^{*}(24) / 100\right)$ & 6771 \\
\hline 37 & \multirow{2}{*}{$\begin{array}{l}\text { Number of HIV positive } \\
\text { general population }\end{array}$} & $\operatorname{Min}\left(=(16)^{*}(27) / 100\right)$ & 17,205 \\
\hline 38 & & $\operatorname{Max}\left(=(16)^{*}(28) / 100\right)$ & 23,689 \\
\hline 39 & \multirow[t]{2}{*}{$\begin{array}{l}\text { Total Number of HIV } \\
\text { positive in the district }\end{array}$} & $\begin{array}{l}\operatorname{Min} \\
(=(29)+(31)+(33)+(35)+(37))\end{array}$ & 22,313 \\
\hline 40 & & $\begin{array}{l}\operatorname{Max} \\
(=(30)+(32)+(34)+(36)+(38))\end{array}$ & 33,925 \\
\hline
\end{tabular}

41 Average Total PLHIV 18-49years, Belgaum district 28,119 $(=(39)+(40) / 2)$

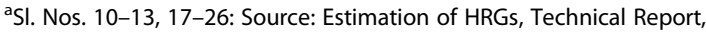
NACO, 2009

They thus achieved high levels of coverage of testing of children identified within the families of index persons living with HIV, as well as timely testing of the HIV exposed newly delivered infants. With well-defined line listing and recruitment processes in place and individualized follow-up, the study was able to quantify and reduce duplication and to better understand the mobility of PLHIV within and outside the district. A number of 
Table 5 Calculation of inflation factors for Strategy $1 \& 2$

\begin{tabular}{|c|c|c|}
\hline Sl. No. & Indicators in the Flow chart for Household information analysis & Number \\
\hline 42 & Estimated 18-49 year HIV positive adult having a child of age $0-14$ years $\left(=(41)^{*}(8)\right)$. & 16,792 \\
\hline 43 & No. of 18-49year HIV positive adult having a child of age $0-14$ years enrolled & 769 \\
\hline 44 & No. of 18-49 year HIV positive adult having a child of age 0-14 years not enrolled (=(42)-(43)). & 16,023 \\
\hline 45 & No. of children $0-14$ years of age for enrolled adults. & 1388 \\
\hline 46 & Average no. of children per enrolled adult (=(45)/(43)). & 1.805 \\
\hline 47 & $\begin{array}{l}\text { Expecting same proportion of children for adults not enrolled, No. of children } 0-14 \text { years of age for adults } \\
\text { not enrolled }\left(=(46)^{*}(44)\right) \text {. }\end{array}$ & 28,921 \\
\hline 48 & Total No. of children 0-14 years of age for 18-49 year HIV positive adult in the district $(=(45)+(47))$. & 30,309 \\
\hline 49 & No. of children 0-14 years of age (for enrolled adults) tested in the study. & 1241 \\
\hline 50 & No. of children 0-14 years of age (for enrolled adults) not tested (=(45)-(49)) & 147 \\
\hline 51 & No. of children $0-14$ years of age for enrolled adults tested positive in the study & 131 \\
\hline 52 & HIV positivity among the tested children $(=(51) /(49))$. & 0.10556 \\
\hline 53 & $\begin{array}{l}\text { Expecting same proportion of HIV positivity among children not tested, No. of HIV positive } 0-14 \text { years children } \\
\text { among untested children }\left(=(52)^{*}(50)\right) \text {. }\end{array}$ & 16 \\
\hline 54 & Total No. of 0-14 years HIV positive children for enrolled 18-49 year HIV positive adult $(=(51)+(53))$. & 147 \\
\hline 55 & Estimated children (0-14 years) HIV positive in the district $\left(=(48)^{*}(52)\right)$. & 3199 \\
\hline 56 & At $95 \% \mathrm{Cl}$ of the prevalence to the estimate & 2594-4094 \\
\hline
\end{tabular}

doctors were also trained in the use of the Modified Integrated Algorithm based on IMCI-HIV guidelines, during the study. The response rates of eligible subjects for HIV testing were high with about $85 \%$ of eligible mothers completing the protocol for follow-up and a similar proportion of eligible families with children completing HIV testing for all children. The study methodology is resource-intensive but may be replicable for other settings and other diseases.

However, we also recognize some limitations in the study. During the study period, many changes in the policy of HIV treatment and prophylaxis for pregnant women occurred including prophylaxis using single-dose Nevirapine, the use of expanded regimens to option B, option $\mathrm{B}+$, and a 'test and treat all HIV positive pregnant women, irrespective of CD4 count, at the time of HIV diagnosis. HIV-related prevention and treatment services were already district-wide and to scale. As a result of prevention and treatment initiatives, there were steady declines in HIV prevalence among the general population, and particularly among pregnant women that led to a delay in completion of the required sample size and follow up in Strategy I. Our results showed that $51 \%$ of all pregnant women had been initiated on Antiretroviral treatment (ART), 42\% during pregnancy, and 9\% after delivery. The effect of the mother's HIV treatment on the incidence of HIV among exposed children has been published [25]. The reduced incidence of HIV among pregnant women delayed achievement of the required sample size for strategy 1, which could have implications in our calculation of prevalence when using the mid-year estimated population size for the district.
However, because of the large overall population size within the Belgaum district, the effect of these annual changes in incidence on estimating the size of children living with HIV, may not be substantial.

A second limitation is the assumption of a similar prevalence among the non-included subjects within the study, during the extrapolation exercise. The number of variables that we had collected was insufficient to completely match the characteristics of responders with nonresponders. The non-response bias could make our estimate higher or lower than the true figure. However, with high levels of coverage as achieved in the study, it is unlikely to change the overall estimate.

There was a delay in initiation of Strategy III, due to delays in the development of the Modified Integrated Algorithm by the national experts/ICMR sub-committee, and the training of health care providers in selected talukas. A large majority (86 of the 97; 89\%) of HIV-positive children detected by this strategy had prior knowledge of their HIV-positive status, indicative of the wide coverage of HIV testing among children in the district. However, despite this, Strategy III did yield new HIV positives among children attending a health facility for reasons other than HIV treatment, thus suggesting one more modality of closing the gap in HIV testing among children who have been exposed to maternal HIV during years when timely age-appropriate HIV testing services were not available or accessible.

Our study only considered children within a family unit. We did not include children who lived without a parent (child-headed homes) or who lived within an institution. Previous studies and Strategy 3 results indicate 
Table 6 Calculation of inflation factors for Strategy 3

\begin{tabular}{|c|c|c|}
\hline Sl. No. & Parameter & Total \\
\hline 1 & Population, Belgaum district, 2001 & $4,207,264$ \\
\hline 2 & Population, Belgaum district, 2011 & $4,779,661$ \\
\hline 3 & Annual Growth Rate & 0.012756 \\
\hline 4 & Projected population, Belgaum district, 2014 & $4,966,110$ \\
\hline 5 & The proportion of 0-14 years population, Belgaum district, 2014 & 0.285874 \\
\hline 6 & Estimated 0-14 year population, Belgaum district, 2014 & $1,419,682$ \\
\hline 7 & Assuming $10 \%$ of children as morbid, estimated no. of children experiencing any morbidity in the district in a year & 141,968 \\
\hline 8 & $\begin{array}{l}\text { Assuming } 70 \% \text { of these morbidities/clinic visits are unique children, expected no. of unique morbid children in the } \\
\text { district in a year }\left(=(7)^{*} 0.7\right.\end{array}$ & 99,378 \\
\hline 9 & During the study period (127 days), a total no. of children reached at HCFs for any morbidity & 33,342 \\
\hline 10 & During the study period (127 days), no. of children screened at HCFs (127 days) & 24,342 \\
\hline 11 & $\begin{array}{l}\text { Assuming } 70 \% \text { of these morbidities/clinic visits are unique children, expected no. of unique morbid children in the } \\
\text { district in a year }\left(=(10)^{*} 0.7\right.\end{array}$ & 17,039 \\
\hline 12 & $\begin{array}{l}\text { No. of children not screened (even if they reached at HCF in } 127 \text { days + had the screening been done for the remaining } \\
238 \text { days in a year) }(=(8)-(10))\end{array}$ & 82,339 \\
\hline 13 & No. of children screened positive (sick children) and enrolled in the study & 527 \\
\hline 14 & No. of unique children screened positive (sick children) and enrolled in the study & 515 \\
\hline 15 & No. of enrolled sick children tested for HIV in the study & 509 \\
\hline 16 & No. of unique enrolled sick children tested for HIV in the study & 497 \\
\hline 17 & No. of tested sick children found positive in the study & 97 \\
\hline 18 & No. of unique tested sick children found positive in the study & 89 \\
\hline 19 & No. of unique newly detected unique HIV positive children among (18) & 11 \\
\hline 20 & Percent of new unique positive children identified among all unique screened positive (sick children) $(=(19) /(16))$ & 0.022 \\
\hline 21 & If all children were tested, new positive children that could be identified from the study $\left(=(14)^{*}(20)\right)$ & 11.40 \\
\hline 22 & Estimated unique children who would have been identified as sick among the unscreened $\left(=[(14) /(11)]^{*}(12)\right)$ & 2488.7 \\
\hline 23 & Estimated no. of unique positive children among the unscreened $\left(=(20)^{*}(22)\right)$ & 55.1 \\
\hline 24 & Total new unique positive children that in the district in a year $(=(23)+(21))$ & 67 \\
\hline 25 & At $95 \%$ Confidence Interval of prevalence to the estimate & $27-103$ \\
\hline
\end{tabular}

that children who were orphans were much more likely to be HIV positive. We did pick up some of the HIVpositive orphans in Strategy 3. However, our sampling design and small numbers did not allow us to estimate the HIV prevalence among orphans. A cross-sectional

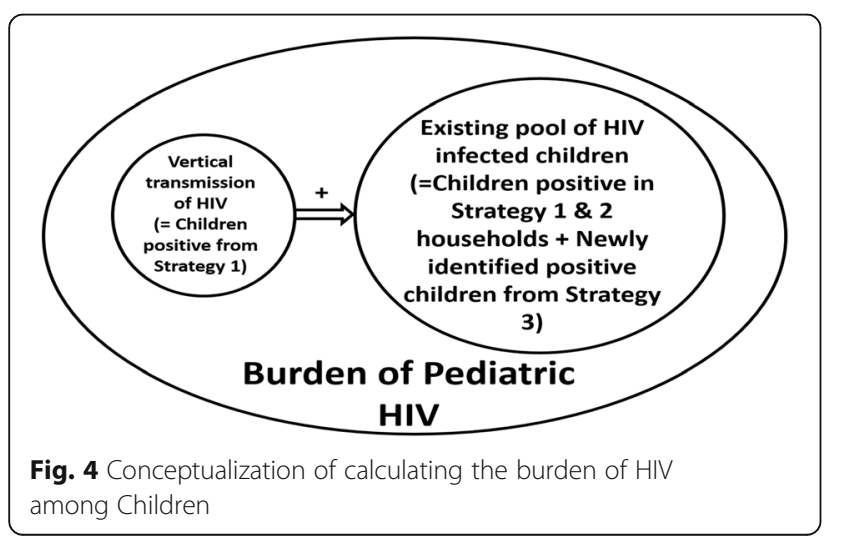

HIV prevalence survey of children living in orphanages could have added value to this study.

Another primary assumption used in strategy I was that the new cases were contributed only by mother-tochild transmission. Recent studies from other countries have indicated that adolescents orphaned as a result of HIV are at greater risk and vulnerability for physical and sexual abuse, including HIV [26]. However, it is expected that these other modes of HIV transmission are rare and the numbers that add to the burden would be

Table 7 Calculation of existing pool of Pediatric ( $<15$ years) HIV infection

\begin{tabular}{lll}
\hline Strategy & HIV Prevalence (\%) & HIV pool of infection \\
\hline $1 \& 2$ & $10.5(95 \%$ Cl: 8.6-13.5) & $3199(95 \%$ Cl: 2594-4094) \\
3 & $2.2^{\mathrm{a}}(95 \% \mathrm{Cl}: 0.9-3.4)$ & $67(95 \% \mathrm{Cl}: 27-103)$ \\
Total & - & $3266(95 \% \mathrm{Cl}: 2621-4197)$ \\
\hline $\begin{array}{l}\text { a additional HIV detected from sick children, not previously identified } \\
\text { in families }\end{array}$
\end{tabular}


minimal. Lastly, we could not integrate mortality and migration estimates into this estimation. The study was not designed to systematically measure mortality among children living with HIV and the information on age-specific mortality rates for children $0-14$ years were not available. We could not calculate age-specific death dates from the current study, as reporting of data for child deaths in the family was not forthcoming and the records were unavailable for verification of the actual date of death, even when they were reported. We observed that HIV prevalence among the $0-5$ year age group was more than twice the HIV prevalence in the children 5-14 years. Interventions for PMTCT or treatment of HIV and AIDS in Belgaum were almost non-existent 10 years before the study period. Therefore, the only plausible reason for this reduction in prevalence in a cross-sectional strategy II could be that most children living with HIV had died. The nonintegration of mortality information into the estimate could have resulted in a higher than the true value.

Despite these limitations, the study is the first of its kind in India and offers new information on methods to estimate Pediatric HIV. We put forward several recommendations for further studies. During the phase II ongoing study, it would also be useful to explore the feasibility of testing the baby for HIV at birth [27], as many maternally exposed new-born died before they were due for the first HIV test at 6 weeks. Testing for HIV at birth is a current recommended CDC guideline that has not yet been adopted in India [28]. Prolonged breastfeeding beyond 6 months, directly increases the risk of HIV infection, especially when it is not exclusive [25]. The acquisition of HIV infection among the children of age group post 24 months need to be further explored by ensuring follow-up HIV testing of the child at least 4-6 weeks following cessation of breastfeeding. A cohort study of all children within sampled family units impacted by HIV would also provide insights into mortality and morbidity among non-infected and HIV positive children, into their nutritional health status, and the influence of the health status of the mothers living with HIV [29]. It is acknowledged that there could be other reasons for HIV transmission to children, especially amongst adolescents [30]. A cohort study among adolescents within these families could indicate the extent to which this occurs.

\section{Conclusions}

The study has used a unique innovative methodology for disease burden estimation of pediatric HIV in a high prevalence district in India, where such data do not exist. Our study estimate of the proportion of pediatric HIV among all PLHIV is $10.4 \%$, higher than the earlier projected figure of $6 \%$. The study methodology, though resource-intensive, can be replicated in similar settings for HIV as well as for other infectious diseases.

\section{Abbreviations}

HIV: Human immunodeficiency virus; AIDS: Acquired immune deficiency syndrome; NACP: National AIDS Control Program; WHO: The World Health Organization; UNAIDS: The United Nations Program on HIV and AIDS; EMTC T: Elimination of Mother-to-Child Transmission of HIV and syphilis; ICTC: Integrated counselling and testing centers; MTCT: Mother-to-child transmission; PPTCT: Prevention of parent-to-child transmission; PMTC $\mathrm{T}$ : Prevention of mother to child transmission; ART: Anti-retroviral therapy; DNA-PCR: Deoxyribonucleic acid -polymerase chain reaction; IMCl-

HIV: Integrated Management of Childhood IIIness- human immunodeficiency virus; IMAl: Integrated Management of Adolescent and Adult Illness (IMAI); KSAPS: Karnataka State AIDS Prevention Society; DAPCU: District AIDS Prevention and Control Unit; PAG: Project Advisory Group; SAP: Statistical Analytical Plan; PLHIV: Persons living with HIV; FSW: Female sex worker; MSM: Men who have sex with men; IDU: Injecting drug users;

EPP: Estimation and Projection Package; CDC: Centers for Disease Control; CD4: Cluster of differentiation 4

\section{Acknowledgments}

We thank the Project Advisory Group chair. Prof N.K. Arora, Dr. Ajay Khera, Dr. Rakesh Lodha, Dr. S.M. Mehendale for their valuable inputs and guidance throughout the implementation of the project. We sincerely thank the Head Division of RBMCH, ICMR Dr. R.S. Sharma for facilitating the project meetings, officials and staff of National AIDS Control Organization, Karnataka State AIDS Prevention Society, Departments of Health and Women and Child Development, and the Belgaum District AIDS Prevention and Control Unit for enabling this study. We acknowledge the contribution of Sub-Committee members Dr. Jagadish Chandra, Dr. Vinod Anand, for their contribution to the Modified Integrated Algorithm. We thank. Dr. Vanamail Perumal for his help in analyzing strategy III data. Furthermore, we would also like to acknowledge with much appreciation the crucial roles of various government and private health care facilities, clinicians, and NGOs working on HIV issues in the Belgaum district. We would like to thank the anonymous reviewers for their valuable suggestions to improve the paper. Finally, we would like to acknowledge the study participants for their consent to participate in the study

\section{Authors' contributions}

AS conceptualized the study, wrote the protocol, coordinated the study, contributed to the analysis and revised the draft manuscript. RW was responsible for study implementation, contributed to the study design, data analysis, and interpretation, wrote the first draft, and revised the final version of the manuscript. RS was responsible for the day-to-day management of field activities, supervised and monitored implementation, and contributed to data analysis. RSP helped with data management and analysis. SI contributed to sample size calculation and reviewed the data analysis. RMP guided the statistical plan of analysis, contributed to data analysis and interpretation. VT was involved in the initial phase of study conceptualization and supervision. All authors reviewed and approved the final draft for submission.

\section{Funding}

Indian Council of Medical Research, New Delhi. The funding agency had no role in study design, collection, analysis, and interpretation of data and in writing the manuscript.

\section{Availability of data and materials \\ The datasets generated and/or analyzed during the current study are not publicly available. The study data is available only to the collaborating scientists. The data may be available on request to the corresponding author Dr. Anju Sinha (apradhandr@gmail.com), Indian Council of Medical Research (ICMR), New Delhi. The data may also be available upon request for some of the collaborating institutions. Data will be sanitized to remove individual identifiers in order to comply with the local data protection laws. All data sharing is subject to National AIDS Control Organisation (NACO) and ICMR approval.}

\section{Declarations}

Ethics approval and consent to participate

The National AIDS Control Organisation (NACO) and the Karnataka State AIDS Prevention Society (KSAPS) provided Regulatory approvals. The 
Institutional Ethics Committee of St John's Medical College and Research Institute, Bengaluru, India provided ethical approval. Informed written consent was taken from all the study participants and the parent, on behalf of children $0-14$ years of age.

\section{Consent for publication}

Not applicable.

\section{Competing interests}

Authors declare that they do not have any competing interests.

\section{Author details}

${ }^{1}$ Division of Reproductive Biology, Maternal and Child Health, Indian Council of Medical Research, New Delhi, India. ${ }^{2}$ St John's Research Institute, Bangalore, India. ${ }^{3}$ Karnataka Health Promotion Trust, Belgaum, India. ${ }^{4}$ Karnataka Health Promotion Trust, Bangalore, India. ${ }^{5}$ Department of Biostatistics, All India Institute of Medical Sciences, New Delhi, India.

Received: 5 January 2021 Accepted: 7 August 2021

Published online: 27 August 2021

\section{References}

1. Frank TD, Carter A, Jahagirdar D, Biehl MH, Douwes-Schultz D, Larson SL, et al. Global, regional, and national incidence, prevalence, and mortality of HIV, 1980-2017, and forecasts to 2030, for 195 countries and territories: a systematic analysis for the global burden of diseases, injuries, and risk factors study 2017. Lancet HIV. 2019;6(12):e831-59. https://doi.org/10.1016/ S2352-3018(19)30196-1.

2. Luzuriaga K, Mofenson LM. Challenges in the elimination of pediatric HIV-1 infection. N Engl J Med. 2016;374(8):761-70. https://doi.org/10.1056/ NEJMra1505256.

3. Stover J, Brown T, Marston M. Updates to the Spectrum/estimation and projection package (EPP) model to estimate HIV trends for adults and children. Sex Transm Infect. 2012;88(Suppl 2):111-6. https://doi.org/10.1136/ sextrans-2012-050640.

4. Age structure and marital status. Office of the Registrar General \& Census Commissioner, India Ministry of Home Affairs, Government of India. Available at: http://censusindia.gov.in/Census_And_You/age_structure_and_ marital_status.aspx: Accessed 02 Jan 2021

5. NACO, India. HIV Estimations: Technical Report. 2017. http://naco.gov.in/ sites/default/files/HIV\%20Estimations\%202017\%20Report_1.pdf. Accessed 02 Jan 2021.

6. WHO. Pediatric HIV Surveillance Among Infants and Children Less Than 18 Years of Age. 2013. https://www.who.int/hiv/pub/surveillance/2013package/ module5/en/. Accessed 02 Jan 2021.

7. Silhol R, Gregson S, Nyamukapa C, Mhangara M, Dzangare J, Gonese E, et al. Empirical validation of the UNAIDS Spectrum model for subnational HIV estimates: case-study of children and adults in Manicaland, Zimbabwe. AIDS. 2017;31:S41-50.

8. Short S, Goldberg R. Children living with HIV-infected adults: estimates for 23 countries in sub-Saharan Africa. PLoS One. 2015;10(11):e0142580. https:// doi.org/10.1371/journal.pone.0142580.

9. Ng'eno B, Mwangi A, Ng'ang'a L, Kim AA, Waruru A, Mukui I, et al. Burden of HIV infection among children aged 18 months to 14 years in Kenya: results from a nationally representative population-based cross-sectional survey. J Acquir Immune Defic Syndr. 2014;66(Supplement 1):S82-8. https:// doi.org/10.1097/QAl.0000000000000118.

10. Mahy M, Penazzato M, Ciaranello A, Mofenson L, Yianoutsos CT, Davies M-A, et al. Improving estimates of children living with HIV from the Spectrum AIDS impact model. AIDS. 2017;31(Supplement 1):S13-22. https://doi.org/1 0.1097/QAD.0000000000001306.

11. Slogrove AL, Powis KM, Johnson LF, Stover J, Mahy M. Estimates of the global population of children who are HIV-exposed and uninfected, 200018: a modeling study. Lancet Glob Health. 2020;8(1):e67-75. https://doi. org/10.1016/S2214-109X(19)30448-6.

12. International Institute for Population Sciences (IIPS) and Macro International. National Family Health Survey (NFHS-3), 2005-06: India: volume I. Mumbai: IIPS; 2007. http://rchiips.org/nfhs/NFHS-3\%20Data/NOL-1/India_volume_I corrected_17oct08.pdf. Accessed 15 Jun 2021
13. NACO. Paving the way to end HIV - National Strategic Plan to End HIV 2017-2024. 2017. http://naco.gov.in/sites/default/files/Paving\%20the\%20Wa y\%20for\%20an\%20AIDS\%2015122017.pdf. Accessed 02 Jan 2021.

14. Start Free Stay Free AIDS Free, UNAIDS. 2020. https://www.unaids.org/en/ resources/documents/2020/start-free-stay-free-aids-free-2020-progressreport. Accessed 15 Jun 2021.

15. Marston M, Becquet R, Zaba B, Moulton LH, Gray G, Coovadia H, et al. Net survival of perinatally and postnatally HIV-infected children: a pooled analysis of individual data from sub-Saharan Africa. Int J Epidemiol. 2011; 40(2):385-96. https://doi.org/10.1093/ije/dyq255.

16. Sheahan A, Feinstein L, Dube Q, Edmonds A, Chirambo CM, Smith E, et al. Early antiretroviral therapy initiation and mortality among infants diagnosed with HIV in the first 12 weeks of life: experiences from Kinshasa, DR Congo and Blantyre. Malawi Pediatr Infect Dis J. 2017;36(7):654-8. https://doi.org/1 0.1097/INF.0000000000001539

17. Sinha A, Nath A, Sethumadhavan R, Isac S, Washington R. Research protocol for an epidemiological study on estimating disease burden of pediatric HIV in Belgaum district, India. BMC Public Health. 2016;16(1). https://doi.org/1 0.1186/s12889-016-3132-8

18. Banandur P, Rajaram S, Mahagaonkar S, Bradley J, Ramesh B, Washington R, et al. Heterogeneity of the HIV epidemic in the general population of Karnataka state, south India. BMC Public Health. 2011;11(Suppl 6):S13.

19. SJRI/KHPT, Mapping of Health Care Facilities in Belgaum District- An ICMR Task Force study, unpublished project report submitted to ICMR, 2014.

20. Sinha A, Washington R, Sethumadhavan R, Perumal V, Potty RS, Isac S. Modified integrated algorithm for detection of HIV among sick children aged 0-14 year seeking care at healthcare facilities in India. Indian Pediatr. 2020;57(7):631-5. https://doi.org/10.1007/s13312-020-1891-x.

21. NACO/NIMS. India HIV Estimations 2015. http://naco.gov.in/sites/default/ files/India/20HIV/20Estimations/202015.pdf. Accessed 02 Jan 2021.

22. NACO. Annual report, 2012-13. http://www.naco.gov.in/sites/default/files/A nnual/20report/202012-13_English.pdf. Accessed 02 Jan 2021.

23. Punyacharoensin N, Viwatwongkasem C. Trends in three decades of HIV/ AIDS epidemic in Thailand by nonparametric back calculation method. AIDS. 2009;23(9):1143-52. https://doi.org/10.1097/QAD.0b013e32832baa1c.

24. Mukherjee S, Ghosh S, Goswami DN, Samanta A. Performance evaluation of PPTCT (prevention of parent to child transmission of HIV) programme: an experience from West Bengal. Indian J Med Res. 2012;136(6):1011-9.

25. Potty RS, Sinha A, Sethumadhavan R, Isac S, Washington R. Incidence, prevalence and associated factors of mother-to-child transmission of HIV, among children exposed to maternal HIV, in Belgaum district, Karnataka. India BMC Public Health. 2019;19(1):386. https://doi.org/10.1186/s12889-0196707-3.

26. Kidman R, Anglewicz P. Are adolescent orphans more likely to be HIVpositive? A pooled data analyses across 19 countries in sub-Saharan Africa. J Epidemiol Community Health. 2016;70(8):791-7. https://doi.org/10.1136/ jech-2015-206744

27. Sandbulte MR, Gautney BJ, Maloba M, Wexler C, Brown M, Mabachi N, et al. Infant HIV testing at birth using point-of-care and conventional HIV DNA PCR: an implementation feasibility pilot study in Kenya. Pilot Feasibility Study. 2019;5(1):18. https://doi.org/10.1186/s40814-019-0402-0.

28. HIV/AIDS Treatment Guidelines. https://aidsinfo.nih.gov/guidelines/html/2/ pediatric-arv/55/diagnosis-of-hiv-infection-in-infants-and-children. Accessed 02 Jan 2021.

29. Isanaka S, Duggan C, Fawzi WW. Patterns of postnatal growth in HIVinfected and HIV-exposed children. Nutr Rev. 2009;67(6):343-59. https://doi. org/10.1111/j.1753-4887.2009.00207.x.

30. Children, HIV and AIDS. 2015. https://www.avert.org/professionals/hiv-socialissues/key-affected-populations/children. Accessed 02 Jan 2021.

\section{Publisher's Note}

Springer Nature remains neutral with regard to jurisdictional claims in published maps and institutional affiliations. 